канд. техн. наук Новак C.B. / Novak S.V., Ph.D. ${ }^{1}$

Przyjęty/Accepted/Принята: 03.03.2015;

Zrecenzowany/Reviewed/Рецензирована: 16.08.2015;

Opublikowany/Published/Опубликована: 30.09.2015;

\title{
Зависимость предела огнестойкости строительных бетонных конструкций от влажности бетона
}

\author{
Fire Resistance Limits of Concrete Constructions Influenced \\ by the Moisture Content of Concrete
}

\author{
Graniczna odporność ogniowa konstrukcji budowlanych z betonu \\ w zależności od jego wilgotności
}

\begin{abstract}
АННОТАЦИЯ
Цель: Определение зависимости предела огнестойкости строительных бетонных конструкций по признаку потери теплоизолирующей способности от влажности бетона.

Проект и методы: Определение значений предела огнестойкости по признаку потери теплоизолирующей способности строительных бетонных конструкций, имеющих разную влажность бетона, проведено решением теплотехнической задачи (прямой задачи теплопроводности), с учетом заданных условий однозначности и теплофизических свойств материала, взятых из Еврокода 2. Решение этой задачи выполнено методом конечных разностей с использованием неявной схемы аппроксимации производных температуры по координате и времени с использованием компьютерной программы Friend. Результаты: Определены значения предела огнестойкости по признаку потери теплоизолирующей способности строительных бетонных конструкций, имеющих влажность бетона $0,1,5$ и 3,0\%. При этом решения прямой задачи теплопроводности проводились с использованием значений коэффициента теплопроводности бетона, определенных как по нижней, так и по верхней граничным кривым, приведенным в Еврокоде 2. Из анализа полученных расчетных данных следует, что отличие между величинами предела огнестойкости, определенными при влажности 1,5 и 3,0\%, от значений, найденных при влажности 0 , составляет 16 и $29 \%$, соответственно. Величина этого отклонения не зависит от толщины конструкции и значений коэффициента теплопроводности бетона. Установлено, что имеет место хорошая сходимость данных по огнестойкости бетонных конструкций, приведенных в Еврокоде 2, с расчетными данными, полученными решением прямой задачи теплопроводности при влажности бетона 1,5 \% и использовании нижней граничной кривой по теплопроводности. Проведена проверка правильности (оценка достоверности) полученных результатов. Для этого выполнено сравнение данных по распределению температур, приведенных в Еврокоде 2, с данными, полученными решением прямой задачи теплопроводности. Максимальное отличие температур составляет $15^{\circ} \mathrm{C}$, что свидетельствует о хорошей сходимости этих данных.

Выводы: Определено, что значение предела огнестойкости строительных бетонных конструкций по признаку потери теплоизолирующей способности значительно зависит от влажности бетона. Поэтому в стандарты или другие нормативные документы необходимо вносить положения относительно области распространения результатов испытаний бетонных конструкций, с учетом наличия существенной зависимости их предела огнестойкости от влажности бетона.
\end{abstract}

Ключевые слова: пожарная безопасность, бетонная конструкция, предел огнестойкости, задача теплопроводности, коэффициент теплопроводности, Еврокод

Вид статьи: оригинальная научная статья

\section{ABSTRACT}

Aim: The purpose of this study is to determine the relationship between fire resistance of concrete building constructions characterised by indications of a decline in heat insulation and moisture content of concrete

Project and methods: Identification of fire resistance limits for building constructions with variable levels of moisture content in concrete, characterised by the loss of insulating properties. This was determined by technical equations dealing with thermal heat engineering

1 Украинский научно-исследовательский институт гражданской защиты / Ukrainian Civil Protection Scientific Research Institute; novak.s.fire@gmail.com; 
(equation for thermal conductivity), reflecting assigned conditions of uniqueness and thermal properties of materials in accordance with Eurocode 2. A solution was facilitated by the finite difference method and implicit outline for the approximation of temperature derivatives within coordinates and time scale, with the aid of "Friend" computer programme.

Results: Fire resistance limits were identified for concrete constructions containing moisture at $0,1.5$ and $3 \%$ levels, which were accompanied by a reduction in thermal insulation ability. A solution to the issue of thermal conductivity was secured with the use of coefficient values for thermal conductivity of concrete using the lower and upper graph limits revealed in Eurocode 2. Analysis of calculated data reveals a difference between fire resistance limit values identified for moisture levels in concrete at $1.5 \%$ and $3 \%$ and 0 are respectively $16 \%$ and $29 \%$. This difference is not dependant on the thickness of the construction or thermal conductivity coefficient of concrete. At the same time it was established that data concerning fire resistance of concrete constructions, described in Eurocode 2 and data from calculations utilising the lower boundary curve for thermal conductivity, which solved the issue of thermal conductivity of concrete containing moisture levels at 1.5 are very similar. The maximum temperature difference is $15 \%$, which indicates good compatibility of data. Conclusions: It is established that the fire resistance limit for concrete constructions, characterized by indications of a decline in heatinsulating ability depends, to a large extent, on moisture content of concrete. Therefore, standards and other normative documents should acknowledge the existence of a significant dependence relationship between fire resistance and moisture content of concrete.

Keywords: fire safety, concrete construction, fire resistance limit, the task of thermal conductivity, the coefficient of thermal conductivity, Eurocode

Type of article: original scientific article

\section{A B S T R A K T}

Cel: Określenie zależności między odpornością ogniową konstrukcji budowlanych z betonu, charakteryzowaną przez utratę zdolności izolacji cieplnej, i wilgotnością betonu.

Projekt i metody: Określenie granicznej wartości odporności ogniowej konstrukcji budowlanych z betonu o różnej wilgotności, która charakteryzuje się utratą jej właściwości izolacyjnych, przeprowadzono poprzez rozwiązanie zadań techniki cieplnej (bezpośrednie równanie przewodzenia ciepła), z uwzględnieniem wprowadzonych warunków jednoznaczności i właściwości termicznych materiałów zgodnie z Eurokodem 2. Rozwiązanie tego problemu przeprowadzono za pomocą metody różnic skończonych i niejawnego schematu aproksymacji pochodnych temperatury według współrzędnych i czasu w programie komputerowym Friend.

Wyniki: Określone zostały wartości graniczne odporności ogniowej konstrukcji z betonu o wilgotności 0, 1,5 i 3\%, objawiające się utratą zdolności termoizolacyjnej. Przy tym rozwiązanie problemu przewodzenia ciepła uzyskane było drogą bezpośrednią z wykorzystaniem wartości współczynnika przewodzenia cieplnego betonu, otrzymanego zarówno na podstawie dolnej jak i górnej krzywej granicznej, podanym w Eurokodzie 2 . Z analizy otrzymanych danych obliczeniowych wynika, że różnica między wartościami granicznymi odporności ogniowej, określonymi przy wilgotności 1,5 i 3\% i wartościami otrzymanymi przy wilgotności $0 \%$ wynoszą odpowiednio $16 \%$ i $29 \%$. Wartość tej różnicy nie zależy od grubości konstrukcji i współczynnika przewodzenia ciepła betonu. Stwierdzono przy tym, że dane na temat odporności ogniowej konstrukcji betonowej, określone w Eurokodzie 2 i dane obliczeniowe, otrzymane w drodze rozwiązania bezpośredniego problemu przewodzenia ciepła przy wilgotności betonu 1,5\% z wykorzystaniem dolnej krzywej granicznej przewodzenia ciepła, są do siebie bardzo zbliżone. Maksymalna różnica temperatur wynosi 15, co wskazuje dobrą zgodność tych danych.

Wnioski: Ustalono, że wartość graniczna odporności ogniowej betonowych konstrukcji budowlanych, charakteryzowanej poprzez utratę zdolności termoizolacyjnych, w dużej mierze zależy od wilgotności betonu. Dlatego do standardów lub innych dokumentów normatywnych należy wnieść poprawki dotyczące obszaru upowszechnienia wyników badań, uwzględniając istnienie dużej zależności między odpornością ogniową a wilgotnością betonu.

Słowa kluczowe: bezpieczeństwo pożarowe, konstrukcja z betonu, graniczna odporność ogniowa, równanie przewodzenia ciepła, współczynnik przewodzenia ciepła, Eurokod

Typ artykułu: oryginalny artykuł naukowy

\section{1. Введение}

При экспериментальном определении пределов огнестойкости строительных бетонных конструкций на огнестойкость, как правило, не проводится определение влажности бетона в образцах, которые подвергаются испытаниям. Это не требуется, в частности, национальными стандартами Украины [1-4], которые устанавливают требования к методам испытаний строительных конструкций на огнестойкость. Однако в этих стандартах указано, что результаты испытаний действительны только для тех образцов, которые поддавались испытаниям, и их нельзя переносить на другие конструкции. При определении области распространения результатов испытаний бетонных конструкций на огнестойкость нерешенным остается вопрос о возможности использования результатов испытаний для конструкций с разной влажностью бетона. Для получения ответа на него необходимо иметь данные о зависимости предела огнестойкости этих конструкций от влажности бетона. Если эта зависимость несущественная (для выбранного диапазона изменения влажности бетона), то можно принять обоснованное решение о распространении результатов испытаний на конструкции з разной влажностью. В ином случае, в стандарты или другие нормативные документы необходимо вносить положения относительно области распространения результатов испытаний бетонных конструкций, с учетом наличия существенной зависимости их предела огнестойкости от влажности бетона. Также, возможно, необходимо будет вносить положение об обязательном измерении 
влажности бетона в образцах бетонных конструкций, которые подвергаются испытаниям на огнестойкость.

С учетом вышеизложенного, целью настоящей работы было поставлено определение зависимости предела огнестойкости строительных бетонных конструкций по признаку потери теплоизолирующей способности от влажности бетона.

\section{2. Метод}

В общем случае, предел огнестойкости $\mathrm{t}_{\mathrm{fr}}$ конструкции соответствует промежутку времени от начала огневого воздействия по стандартному температурному режиму до наступления одного из нормируемых для рассматриваемой конструкции предельных состояний по огнестойкости [1]. Одним из таких состояний, которое установлено для строительных ограждающих конструкций - стен и перекрытий, является потеря теплоизолирующей способности конструкции, признаком которой есть превышение средней температуры на необогреваемой поверхности конструкции над начальной средней температурой этой поверхности на $140^{\circ} \mathrm{C}$ или превышение температуры в любой точке необогреваемой поверхности конструкции над начальной температурой в этой точке на $180^{\circ} \mathrm{C}[1-4]$. Для определения указанного выше промежутка времени расчетным путем следует решать теплотехническую задачу - прямую задачу теплопроводности (далее - ПЗТ), с учетом заданных условий однозначности и значений теплофизических свойств материала, который применяется в строительной конструкции [5]. В европейских стандартах [6-12] (Еврокодах), устанавливающих методы расчета огнестойкости строительных бетонных, стальных и других конструкций, приводятся параметры (значения коэффициентов теплоотдачи, температуры среды в зависимости от времени огневого воздействия, теплофизических и прочностных свойств материалов и др.), которые необходимы для получения однозначных результатов расчета. Для бетонных конструкций такие параметры приведены в Еврокоде 2 [7]. В частности, в нем даны зависимости от температуры удельной теплоемкости бетона с влажностью $0,1,5$ и 3,0\%, приведенные на рис. 1, и плотности бетона, а также указано, что значения коэффициента теплопроводности бетона должны быть в интервале, который ограничен верхней и нижней граничными кривыми 1, 2, показанными на рис. 2.

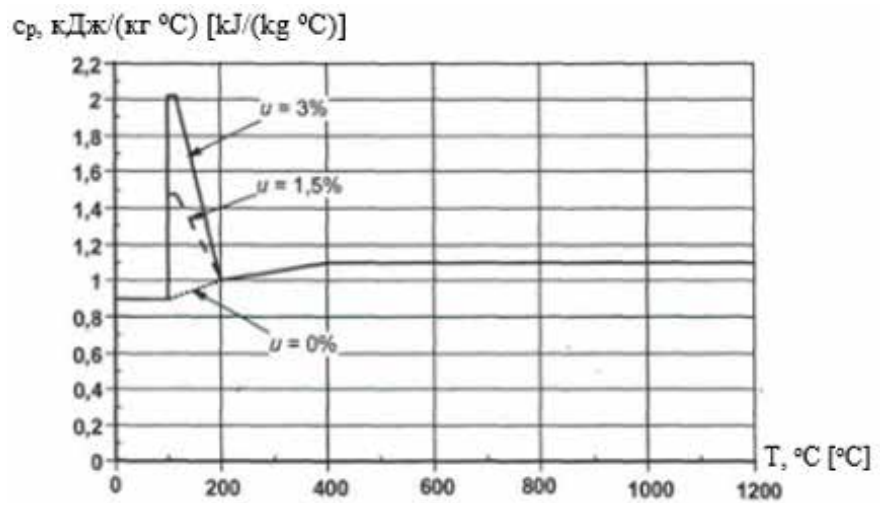

Рис. 1. Зависимость от температуры удельной массовой теплоемкости бетона с влажностью $u=0 ; 1,5$ и 3\%, приведенная в Еврокоде 2 [7]

Fig. 1. Dependence on the temperature of the specific mass heat of concrete with the humidity of $u=0 ; 1,5$ and $3 \%$, given in Eurocode 2 [7]

$\lambda, \mathrm{BT} /\left(\mathrm{m}^{\circ} \mathrm{C}\right)\left[\mathrm{W} /\left(\mathrm{m}^{\circ} \mathrm{C}\right)\right]$

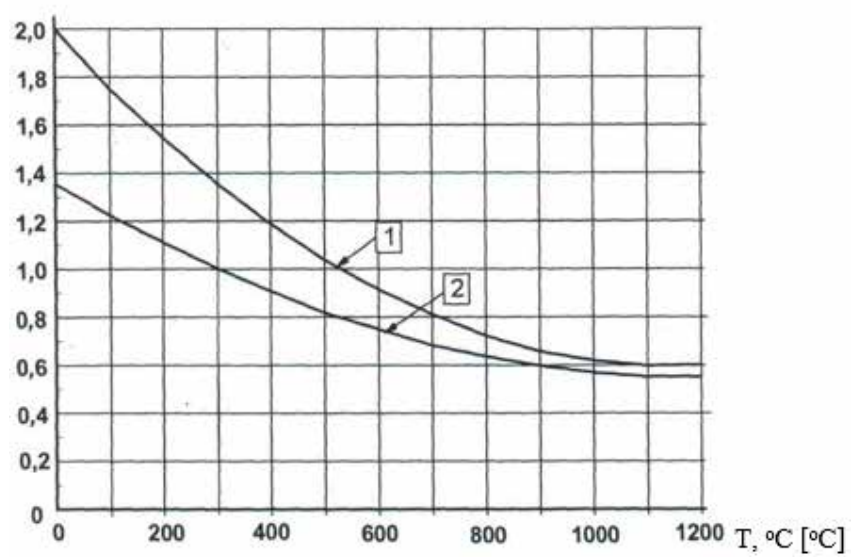

Рис. 2. Зависимость коэффициента теплопроводности бетона от температуры, приведенная в Еврокоде 2 [7]: 1 - верхняя граница $\lambda_{\text {high }} ; 2$ - нижняя граница $\lambda_{\text {low }}$

Fig. 2. Dependence of the coefficient of the thermal conductivity of concrete on the temperature, given in Eurocode 2 [7]: 1 - upper boundary of $\lambda_{\text {high }} ; 2$ - lower boundary of $\lambda_{\text {low }}$ 
Для расчета огнестойкости конструкций с разной влажностью бетона решением ПЗТ применена математическая модель теплового состояния конструкции для одномерного процесса нестационарной теплопроводности, которая представляет собой уравнение теплопроводности

$$
\begin{aligned}
\mathrm{c}_{\mathrm{v}}(\mathrm{T}) \frac{\partial \mathrm{T}}{\partial \mathrm{t}} & =\frac{\partial}{\partial \mathrm{x}}\left[\lambda(\mathrm{T}) \frac{\partial \mathrm{T}}{\partial \mathrm{x}}\right] \\
\mathrm{T} & =\mathrm{T}(\mathrm{x}, \mathrm{t}),
\end{aligned}
$$

с начальным условием $\mathrm{T}(\mathrm{x}, 0)=\mathrm{T}_{0}=$ const в области решения $\mathrm{x}_{1} \geq \mathrm{x} \geq \mathrm{x}_{0}$ для однослойной стенки с граничным условием радиационно-конвективного теплообмена на ее обогреваемой поверхности (граница $\left.\mathrm{x}=\mathrm{x}_{0}\right)$ с температурой $\mathrm{T}(0, \mathrm{t})$ и горячими газами с температурой $\mathrm{T}_{\mathrm{r}}$

$$
\lambda \frac{\partial \mathrm{T}(0, \mathrm{t})}{\partial \mathrm{x}}=\alpha^{*}\left[\mathrm{~T}(0, \mathrm{t})-\mathrm{T}_{\Gamma}(\mathrm{t})\right]
$$

где

$$
\alpha^{*}=\alpha_{\mathrm{c}}+\frac{\mathrm{C}_{0} \varepsilon}{T_{s}(t)-\mathrm{T}\left(x_{2}, \mathrm{t}\right)}\left\{\left[\frac{\mathrm{T}_{\mathrm{s}}(t)+273}{100}\right]^{4}-\left[\frac{\mathrm{T}\left(x_{2}, \mathrm{t}\right)+273}{100}\right]^{4}\right\}
$$

и граничным условием конвективного теплообмена со стороны окружающей среды на границе $\mathrm{x}=\mathrm{x}_{1}$

$$
\lambda \frac{\partial \mathrm{T}\left(\mathrm{x}_{1}, \mathrm{t}\right)}{\partial \mathrm{x}}=\alpha^{* *}\left[\mathrm{~T}\left(\mathrm{x}_{1}, \mathrm{t}\right)-\mathrm{T}_{0}\right]
$$

В (1)-(4) $c_{v}=c_{p} \rho-$ удельная объемная теплоемкость, $\mathrm{c}_{\mathrm{p}}$ - удельная массовая теплоемкость, $\rho$ - плотность, $\lambda$ - коэффициент теплопроводности, T- температура, $\mathrm{t}$ - время огневого воздействия, $\mathrm{x}-$ координата, $\alpha^{*}$ - коэффициент теплоотдачи от горячих газов к нагреваемой поверхности конструкции, $\alpha^{* *}-$ коэффициент теплоотдачи от необогреваемой поверхности конструкции в окружающую среду (воздух), $\mathrm{C}_{0}-$ излучательная способность абсолютно черного тела $\left(\mathrm{C}_{0}=5,67\right), \varepsilon-$ коэффициент теплового излучения нагреваемой поверхности конструкции; $\mathrm{T}_{\Gamma}$ - температура горячих газов; $\mathrm{T}_{0}$ - начальная температура и температура окружающей среды. Согласно положениям Еврокода 2 [7] при расчетах коэффициент теплоотдачи $\alpha *$ принимается равным $25 \mathrm{BT} /\left(\mathrm{M}^{2 \circ} \mathrm{C}\right)$, коэффициент теплового излучения $\varepsilon=0,7$, коэффициент теплоотдачи $\alpha^{* *}=9 \mathrm{BT} /\left(\mathrm{M}^{2 \circ} \mathrm{C}\right)$, температура $\mathrm{T}_{0}=20^{\circ} \mathrm{C}$.

Постановка задачи определения предела огнестойкости ограждающей конструкции (стены, перекрытия и др.) по признаку потери ее теплоизолирующей способности путем решения прямой задачи теплопроводности следующая. Решением математической модели (1)-(4) необходимо определить значения температуры $\mathrm{T}\left(\mathrm{x}_{1}, \mathrm{t}\right)$ на необогреваемой поверхности конструкции для разных моментов времени огневого воздействия по стандартному температурному режиму и на основании этих данных установить время $\mathrm{t}_{\mathrm{fr}}$, при котором температура этой поверхности составляет $160^{\circ} \mathrm{C}$.

\section{3. Результаты}

Математическая модель (1)-(4) интегрировалась численно методом конечных разностей с использованием неявной схемы аппроксимации производных температуры по координате х и времени t. При решении ПЗТ значения удельной теплоемкости бетона брались по зависимостям, приведенным на рис. 1 для бетона с влажностью 0, 1,5 и 3,0\%, взятым из Еврокода 2 [7]. Плотность бетона принималась зависящей от температуры и определялась по формулам, приведенным в Еврокоде 2 [7, с. 31]. При температуре $20^{\circ} \mathrm{C}$ плотность бетона составляет 2300 кг/м³. Решения ПЗТ проводились с использованием значений коэффициента теплопроводности бетона, определенных как по нижней $\lambda_{\text {low }}$ так и по верхней $\lambda_{\text {high }}$ граничным кривым, приведенным на рис. 2, и компьютерной программы Friend [13]. Полученные результаты даны в таблице 1. В этой таблице также приведены данные о пределах огнестойкости строительных бетонных конструкций, взятые из Еврокода 2 [7, с. 56]. Относительно этих данных в Еврокоде 2 [7, с. 46] указано, что „приведенные в нем таблицы разработаны на эмпирической основе и подтверждены теоретической оценкой и испытаниями. Данные действительны для всего диапазона теплопроводности”. Информация о влажности бетона в этих конструкциях в Еврокоде 2 [7] не приводится.

\begin{tabular}{|c|c|c|c|c|c|c|c|}
\hline \multirow{3}{*}{$\begin{array}{c}\text { Толщина конструкции / } \\
\text { Thickness of the construction } \\
\text { d, мM [mm] }\end{array}$} & \multicolumn{7}{|c|}{$\begin{array}{c}\text { Предел огнестойкости / Fire resistance limit } \\
\mathbf{t}_{\mathrm{fr}} \text { мин [min] }\end{array}$} \\
\hline & \multicolumn{2}{|c|}{$\mathbf{u}=\mathbf{0} \%$} & \multicolumn{2}{|c|}{$\mathrm{u}=\mathbf{1 , 5 \%}$} & \multicolumn{2}{|c|}{$\mathbf{u}=\mathbf{3} \%$} & \multirow{2}{*}{$\begin{array}{l}\text { Данные из Еврокода } 2[7, \text { c. 56] } \\
\text { Data from Eurocode } 2[7, \text { s. 56] }\end{array}$} \\
\hline & $\lambda_{\text {low }}$ & $\lambda_{\text {high }}$ & $\lambda_{\text {low }}$ & $\lambda_{\text {high }}$ & $\lambda_{\text {low }}$ & $\lambda_{\text {high }}$ & \\
\hline 60 & 31 & 25 & 36 & 29 & 40 & 32 & 30 \\
\hline 80 & 50 & 39 & 57 & 45 & 64 & 50 & 60 \\
\hline 100 & 73 & 56 & 84 & 65 & 93 & 73 & 90 \\
\hline 120 & 100 & 56 & 116 & 89 & 128 & 99 & 120 \\
\hline 150 & 149 & 114 & 173 & 132 & 192 & 148 & 180 \\
\hline 175 & 198 & 151 & 229 & 175 & 255 & 195 & 240 \\
\hline
\end{tabular}

Таблица 1. Значения предела огнестойкости бетонных конструкций по признаку потери теплоизолирующей способности, полученные при разной влажности бетона

Table 1. Values of the fire resistance of concrete constructions according to the loss of the heat-insulating ability, with the different humidity of the concrete

Источник: Собственная разработка Source: Own elaboration. 
На рис. 3 приведена зависимость предела огнестойкости конструкции от влажности бетона, построенная по данным таблицы 1 для варианта изменения коэффициента теплопроводности бетона по верхней граничной кривой $\lambda_{\text {high }}$.

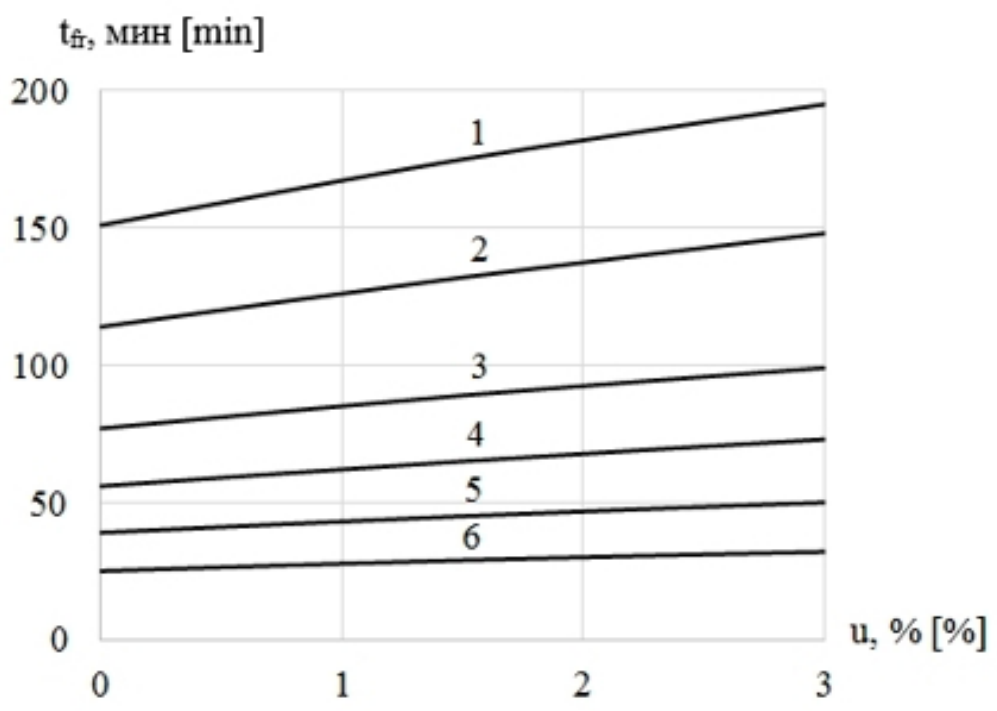

Рис. 3. Зависимость предела огнестойкости конструкции от влажности бетона для разных значений ее толщины $\mathrm{d}_{\mathrm{c}}$ (мм): $1-175 ; 2-150 ; 3-120 ; 4-100 ; 5-80 ; 6-60$

Fig. 3. Dependence of the limit of the fire resistance of construction from the humidity of concrete for the different values of its thickness $d_{c}(\mathrm{~mm}): 1-175 ; 2-150 ; 3-120 ; 4-100 ; 5-80 ; 6-60$

Источник: Собственная разработка Source: Own elaboration.

В таблице 2 приведены относительные отклонения $\delta_{\mathrm{tu}}$ значений предела огнестойкости $\mathrm{t}_{\mathrm{frui}}$ бетонных конструкций, полученных при влажности 1,5 и 3,0\%, от величин $\mathrm{t}_{\text {fro }}$, найденных при $\mathrm{u}=0$. Расчет этих отклонений приводился по следующей формуле:

$$
\delta_{\mathrm{tu}}=100\left(\mathrm{t}_{\text {fr ui }}-\mathrm{t}_{\text {fro }}\right) / \mathrm{t}_{\text {fro }}
$$

На рис. 4 представлена зависимость этого отклонения от влажности бетона, построенная по данным таблицы 2.

\section{4. Дискуссия}

Из анализа приведенных данных следует, что значение предела огнестойкости бетонных конструкций по признаку потери теплоизолирующей способности значительно зависит от влажности бетона. Отличие между величинами предела огнестойкости, полученными при влажности 1,5 и 3,0\%, от значений, найденных при $\mathrm{u}=0$, составляет 16 и 29\%, соответственно. Значение этого отклонения не зависит от толщины конструкции и величины коэффициента теплопроводности бетона.

Таблица 2. Отклонения значений предела огнестойкости бетонных конструкций, полученных при разной влажности бетона.

Table 2. Deviations of the values of the limit of the fire resistance of the concrete constructions, obtained with the different humidity of concrete.

\begin{tabular}{|c|c|c|c|c|}
\hline \multirow{3}{*}{$\begin{array}{c}\text { Толщина конструкции } \\
\text { Thickness of the construction } \\
\mathbf{d}_{\mathrm{c}}, \mathbf{M M}[\mathrm{mm}]\end{array}$} & \multicolumn{4}{|c|}{$\begin{array}{c}\text { Относительное отклонение } \\
\text { Relative deflection } \boldsymbol{\delta}_{\mathrm{tu}}, \%\end{array}$} \\
\hline & \multicolumn{2}{|c|}{$\mathrm{u}=1,5 \%$} & \multicolumn{2}{|c|}{$\mathbf{u}=\mathbf{3} \%$} \\
\hline & $\lambda_{\text {low }}$ & $\lambda_{\text {high }}$ & $\lambda_{\text {low }}$ & $\lambda_{\text {high }}$ \\
\hline 60 & 16 & 16 & 29 & 28 \\
\hline 80 & 15 & 15 & 28 & 28 \\
\hline 100 & 15 & 16 & 28 & 29 \\
\hline 120 & 16 & 16 & 28 & 29 \\
\hline 150 & 16 & 16 & 29 & 29 \\
\hline 175 & 16 & 16 & 29 & 29 \\
\hline
\end{tabular}

Источник: Собственная разработка

Source: Own elaboration. 


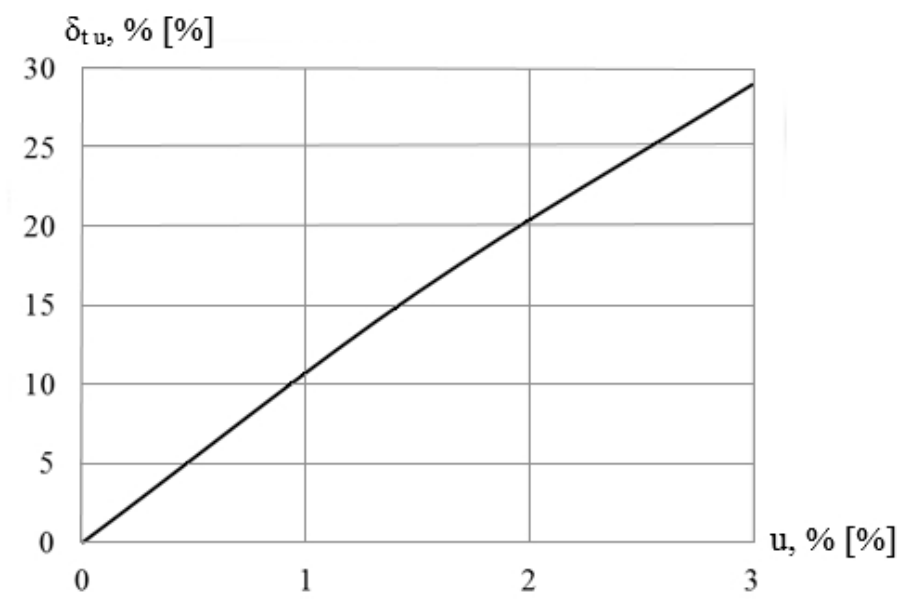

Рис. 4. Зависимость относительного отклонения $\delta_{\text {tu }}$ от влажности бетона

Fig. 4. Dependence of the relative deflection of $\delta_{t u}$ from the humidity of the concrete

Источник: Собственная разработка

Source: Own elaboration.

Имеет место хорошая сходимость данных по огнестойкости строительных бетонных конструкций, приведенных в Еврокоде 2 [7, с. 56], с расчетными данными, полученными решением ПЗТ при влажности бетона 1,5 \% и использовании нижней граничной кривой по теплопроводности $\lambda_{\text {low }}$ (см. табл.1 и рис. 5). Отличие в этих данных не превышает 7\% при толщине конструкции от 80 мм до 175 мм и имеет максимальное значение $20 \%$ при толщине 60 мм.

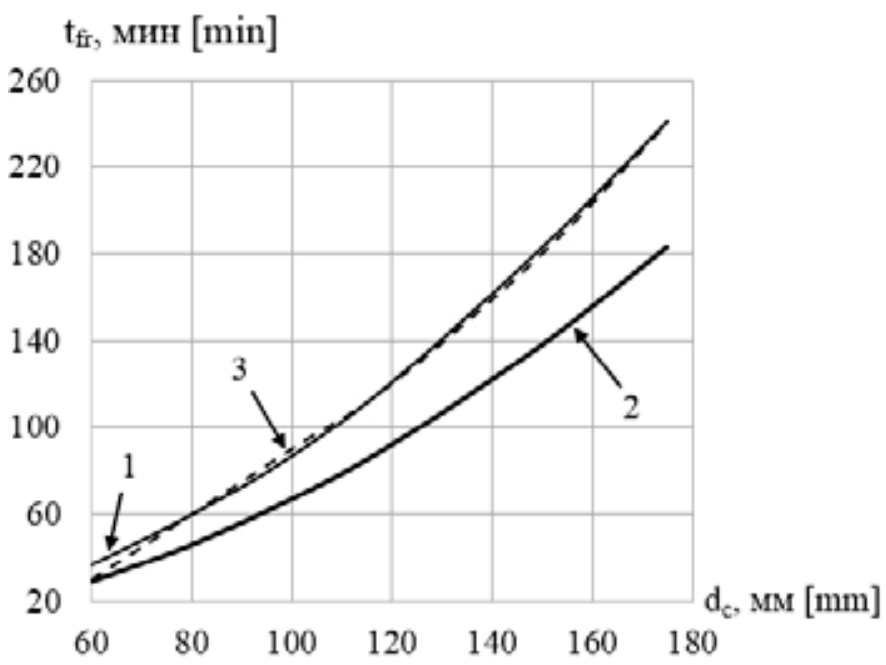

Рис. 5. Зависимость предела огнестойкости бетонной конструкции от ее толщины:

1 - расчет по нижней граничной кривой при $\mathrm{u}=1,5 \% ; 2$ - расчет по верхней граничной кривой $\mathrm{u}=1,5 \% ; 3$-данные из Еврокода $2[7$, с. 56]

Fig. 5. Dependence of the limit of the fire resistance of the concrete construction from the thickness:

1 - calculation according to the lower boundary curve with $u=1,5 \% ; 2$ - calculation according to the upper boundary curve $\mathrm{u}=1,5 \% ; 3$ - data from Eurocode $2[7, \mathrm{s.} 56]$

Проведена проверка правильности (оценка достоверности) полученных с использованием математической модели (1)-(4) результатов путем сравнения данных распределений температур, приведенных в Еврокоде 2 [7, с. 76], с результатами решения прямой задачи теплопроводности.

В Еврокоде 2 [7, с. 76] приведены графики зависимости температуры от расстояния от нагреваемой поверхности бетонной конструкции толщиной 200 мм (рис. 6а) для моментов времени 30, 60, 90, 120, 180, 240 минут (температурные кривые R30 - R240). B Еврокоде 2 [7, с. 75] указано, что эти зависимости определены расчетным путем для бетона с влажностью $1,5 \%$, имеющего значения коэффициента теплопроводности в соответствии с нижней граничной кривой. Для этой конструкции решением ПЗТ получена зависимость температуры от расстояния для момента времени 180 мин. Сравнение полученных результатов с данными Еврокода 2 [7, с. 76] приведено на рисунке 66. Максимальное отличие температур составляет $15^{\circ} \mathrm{C}$, что свидетельствует о хорошей сходимости данных, полученных решением ПЗТ, с данными, приведенными в Еврокоде 2 [7, с. 76]. 


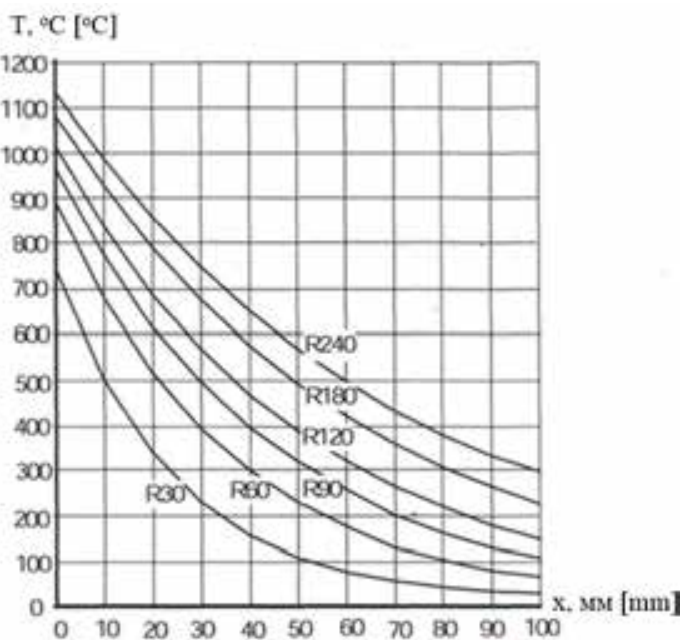

a) / a)

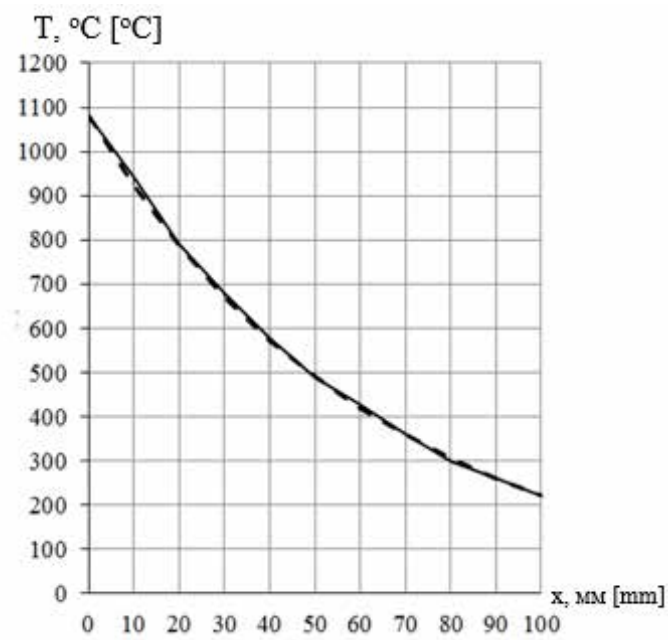

б) / b)

Рис. 6. Зависимость температуры от расстояния от нагреваемой поверхности бетонной конструкции толщиной 200 мм для моментов времени 30, 60, 90, 120, 180, 240 мин (кривые R30 - R240), приведенная в Еврокоде 2 (a), и эта зависимость для момента времени 180 мин (б): сплошная кривая - решение ПЗТ; пунктирная кривая - данные Еврокода 2 [7, с. 76].

Fig. 6. Dependence of temperature on the distance from the exposed surface of concrete construction with a thickness of $200 \mathrm{~mm}$ for moments of time 30, 60, 90, 120, 180, 240 min (curves R 30 - R240), given in the Eurocode 2 (a), and this dependence for moment of the time of $180 \mathrm{~min}$ (b): unbroken curve - solution of direct problem of thermal conductivity; broken curve - data of Eurocode $2[7$, s. 76].

\section{5. Выводы}

Определено, что значение предела огнестойкости строительных бетонных конструкций по признаку потери теплоизолирующей способности значительно зависит от влажности бетона. Отличие между величинами предела огнестойкости, полученными при влажности 1,5 и $3,0 \%$, от значений, найденных при влажности $u=0$, составляет 16 и 29\%, соответственно. Значение этого отклонения не зависит от толщины конструкции и величины коэффициента теплопроводности бетона. Поэтому в стандарты или другие нормативные документы необходимо вносить положения относительно области распространения результатов испытаний бетонных конструкций, с учетом наличия существенной зависимости предела их огнестойкости от влажности бетона. Также необходимо вносить положение об обязательном измерении влажности бетона в образцах бетонных конструкций, которые подвергаются испытаниям на огнестойкость.

Достоверность полученных результатов подтверждается хорошей сходимостью данных по огнестойкости строительных бетонных конструкций и распределений температур, приведенных в Еврокоде 2, с расчетными данными, полученными решением прямой задачи теплопроводности с использованием математическоsй модели (1)-(4). Отличие в данных по огнестойкости не превышает $20 \%$, а отличие по температуре не превышает $15^{\circ} \mathrm{C}$.

\section{Литература}

[1] DSTU B V.1.1-4-98* Zashchita ot pozhara. Stroitel'nyye konstruktsii. Metody ispytaniy na ognestoykost.' Obshchiye trebovaniya.

[2] DSTU B V.1.1-15:2007 Zashchita ot pozhara. Peregorodki. Metod ispytaniya na ognestoykost' (EN 1364-1:1999, NEQ).

[3] DSTU B V.1.1-19:2007 Zashchita ot pozhara. Nesushchiye steny. Metod ispytaniya na ognestoykost' (EN 1365-1:1999, MOD).

[4] DSTU B V.1.1-20:2008 Zashchita ot pozhara. Perekrytiya i pokrytiya. Metod ispytaniya na ognestoykost' (EN 1365-2:1999, NEQ).

[5] Gosudarstvennyye stroitel'nyye normy Ukrainy DBN V 1.1-7-2002* Pozharnaya bezopasnost' ob"yektov stroitel'stva.

[6] EN 1991-1-2:2002 Eurocode 1: Actions on structures - Part 1-2: General actions - Actions on structures exposed to fire.

[7] EN 1992-1-2:2004 Eurocode 2: Design of concrete structures - Part 1-2: General rules - Structural fire design.

[8] EN 1993-1-2:2005 Eurocode 3: Design of steel structures - Part 1-2: General rules - Structural fire design.

[9] EN 1994-1-2:2005 Eurocode 4. Design of composite steel and concrete structures - Part-2: General rules. Structural fire design.

[10] EN 1995-1-2:2004 Eurocode 5 - Design of timber structures - Part 1-2: General - Structural fire design.

[11] EN 1996-1-2:2005 Eurocode 6: Design of masonry structures - Part 1-2: General rules - Structural fire design.

[12] EN 1999-1-2:2002 Eurocode 9: Design of aluminium structures - Part 1-2: Structural fire design.

[13] Krukovskiy P., Obratnyye zadachi teplomassoperenosa (obshchiy inzhenernyy podkhod), izdatel'stvo ITTF NAN Ukrainy, Kiyev, 1996. 
канд. техн. наук Новак Сергей Викторович - сотрудник Украинского научно-исследовательского института гражданской защиты. Автор более 200 публикаций в научных журналах, сборниках материалов научно-практических конференций и семинаров; разработчик более 30 национальных стандартов Украины и 15 государственных строительных норм. Основные научные интересы: исследование огнестойкости строительных конструкций и противопожарных преград экспериментально-расчетными методами; оценка огнестойкости конструкций методами, которые основаны на рассмотрении сценариев реального и условного пожара и математическом моделировании теплового состояния конструкций при пожаре; внедрение методов оценки огнестойкости, которые применяются в европейских нормах по проектированию строительных конструкций. 